\section{Baby walkers . . . time to take a stand?}

Sir,

I agree with the report of Gleadhill et al on the dangers of baby walkers. ${ }^{1}$ I think, however, that the fact that two of the three cases they describe involved infants no older than 7 months who were left unsupervised in these baby walkers indicates that there was insufficient parental care. This would certainly appear to be so at the time of the accidents. Placing a young infant in a baby walker and thus giving him uncontrollable speed and mobility without supervision is as irresponsible as allowing a 6 year old to drive a motor car.

My experience is that those parents who are somewhat inadequate, depressed, or socially deprived are among the most ardent users of baby walkers. The infant is placed in this and then left to 'amuse' himself. These parents often have little insight into normal child development and are unprepared for the consequences of the mobility suddenly achieved by the infant.

Another factor is that it is usually the infant who is irritable and hyperactive who is most often placed in a baby walker. The combination of a hyp̈ractive adventurous infant and an insufficiently observant parent is also found in other cases of accidental injuries and poisoning. ${ }^{2}$ Education and warning labels may help but unfortunately these are often the families who are least amenable to advice on child care and safety. ${ }^{3}$ Even if the baby walker complies with the strictest safety regulations accidents will still occur-especially from overturning. The total banning of the sale of baby walkers may be the only resort if these accidents are to be prevented completely.

\section{References}

' Glcadhill DNS, Robson WJ, Cudmore RE, Turnock RR. Baby walkers . . . time to take a stand? Arch Dis Child 1987:62:491-4.

2 Craft AW. Circumstances surrounding deaths from accidental poisoning 1974-80. Arch Dis Child 1983;58:544-6.

3 Polnay L. A service for problem families. Arch Dis Child 1985;60:887-90.

A M Oudesluys-MurPhy Department of Paediatrics, Zuiderziekenhuis, Groene Hilledijk 315, 3075 EA Rotterdam,

The Netherlands

Sir,

I share the concern about the safety of baby walkers, expressed by Gleadhill et al. ${ }^{\prime}$

The susceptibility of infants in baby walkers to burns was pointed out by Colville and his colleagues in Belfast, ${ }^{2}{ }^{3}$ who reported 31 severe burns over a decade, showing the hazards to which babies were being exposed.

Our own data confirm the conclusions of Gleadhill et al that these devices are still a source of serious injury, even after strenuous efforts by the British Standards Institute and by public information campaigns. Of 160 burns severe enough to merit admission to the Leicester Royal Infirmary Burns Unit over the last year, $3(1.9 \%)$ were associated with the use of baby walkers. This represents
$22.2 \%$ of children of baby walker age ( 8 to 14 months). Of 400 sequential burns over the last six months requiring outpatient treatment, however, none was connected with baby walkers.

Thus not only are these devices still causing burns, but the kind of burns they cause to a child robbed of his normal protective reflexes by these 'mobile straight jackets' are generally of a serious nature. I therefore agree that it is indeed 'time to take a stand' on the use of the baby walker devices.

\section{References \\ 1 Gleadhill DNS, Robson WJ, Cudmore RE, Turnock RR. Baby walkers . . . time to take a stand? Arch Dis Child 1987;62:491-4. \\ 2 Colville J. Infant walking aid hazard. Lancet 1966;i:209. \\ ${ }^{3}$ Miller R, Colville J, Hughes MC. Burns to infants using walking aids. Injury 1975;7:8-10.}

M A BirChALL

Leicester Royal Infirmary, Leicester LE1 5WW

\section{Vasoactivity of the major intracranial arteries in newborn infants}

Sir,

We read with interest the paper by Drayton and Skidmore but suggest that their conclusions cannot be justified by the data provided in their paper. The statement that the major cerebral arteries are the main site of autoregulation is based entirely on the observation that there is no change in the cerebral blood flow (CBF) as measured by their Doppler method. We are not convinced that the method they used is valid and appropriate to the measurement of CBF.

Absolute flow is difficult to measure accurately using Doppler ultrasound. ${ }^{2}$ The method used by Drayton and Skidmore is particularly inaccurate as small errors in the measurement of flow made at two points will lead to large errors in the calculated differences; although the two flow estimates are subtracted, the error is additive. Even under ideal conditions (a non-reactive circular aorta) accuracy of measurement of the aorta cannot be better than the order of a wavelength of ultrasound and will lead to an error of about $6 \%$ when measuring the diameter of the immature aorta (about $8 \mathrm{~mm}$ ) and a $12 \%$ error in a cross sectional area. We calculate that for an infant weighing $1500 \mathrm{~g}$ where about $30 \%$ of the flow in the ascending aorta perfuses the head and arms and $80 \%$ of this perfuses the brain, then the smallest likely error in calculating the flow to the upper part of the body by the subtraction method is of the order of $50 \%$. Details of these calculations are available on request to us. Our calculations are based on four assumptions: a closed ductus arteriosus, a brain weight of $150 \mathrm{~g}, \mathrm{CBF}$ of $60 \mathrm{ml} / 100 \mathrm{~g} / \mathrm{minute}^{1}{ }^{1}$ and a cardiac output of $260 \mathrm{ml} / \mathrm{minute} / \mathrm{kg}^{3}{ }^{3}$

There is a great deal of evidence to support the contention that regulation of CBF is mediated by the microvasculature. Drayton and Skidmore have, however, chosen to ignore these data in suggesting that the major cerebral arteries perform the main role in regulating blood 
flow. We do not disagree that in mature animals (and possibly humans) the major cerebral arteries may show vasoactivity in response to changing patterns of flow, but we can find no data from the work of Drayton and Skidmore to support this assertion in the premature infant. Tye onus is on them to show that their method for measuring $\mathrm{CBF}$ correlates with any other independent method either in humans or in animals before we can accept that major cerebral arteries mediate cerebral autoregulation in the preterm neonate.

\section{References}

1 Drayton MR, Skidmore R. Vasoactivity of the major intracranial arteries in newborn infants. Arch Dis Child 1987;62: 236-40.

2 Evans DH. Can ultrasonic duplex scanners really measure volumetric flow? In: Evans JA, ed. Medical ultrasound. London: IPSM, 1986.

${ }^{3}$ Walther FJ, Siassi B, Ramadan NA, Ananda AK, Wu PYK. Pulsed Doppler determinations of cardiac output in neonates: normal standards for clinical use. Pediatrics 1985;76:829-33.

\section{I Levene, D H Evans, L N J Archer, and D SHORTLAND Departments of Child Health and Medical Physics, Leicester University School of Medicine, Leicester LEI $5 W W$}

\section{Drs Drayton and Skidmore comment:}

Our finding of a large increase in cerebral artery blood velocity during the first $\mathbf{4 8}$ hours of life but no change in a measure of cerebral blood flow (CBF) has important implications for simpler Doppler techniques of assessing the cerebral circulation. Levene et al question whether limitations of our volumetric technique could explain the absence of any apparent increase in CBF.

It is true that if there had been progressive and unidentified constriction of the aortic isthmus over the 48 hours, CBF might indeed have risen. We know of only two detailed studies of sequential changes in the size of the isthmus both of which conclude that there is a progressive but slow relative increase in the diameter of the isthmus from birth. ${ }^{12}$ The isthmus has a different embryological origin from the ductus arteriosus, and is histologically indistinguishable from the rest of the aortic arch, which decreases the likelihood that it constricts in a similar manner to the ductus itself. ${ }^{3} \mathrm{M}$ mode measurement of the diameter of the isthmus in our infants was frequently impossible but measurements from the real time image did not suggest that there were any progressive changes in diameter over the time course of our studies. The oval section of the aortic isthmus may introduce a small but constant error in our calculations but this is irrelevant to this discussion of change in velocity and flow.

In our opinion the basis for their calculation of potential error in our technique is inappropriate. Our own calculations, available from us on request, give a potential error in mean CBF of $9 \%$ for the preterm group and $16 \%$ for the term group, both well below the percentage change observed in cerebral artery velocity.

We may approach the same problem empirically by using the dispersion in our data that incorporates error and variation from all sources to calculate the confidence limits for any change. We can thus be $95 \%$ certain that any change in CBF between 1.5 and 48 hours was between $+32 \%$ and $-30 \%$ for the preterm group and $+28 \%$ and $-33 \%$ for the term group.

Levene et al conclude from the work of Kennedy et al that there is an increase in CBF in the first few days of life in dogs born at term. Their results, however, showed no increase in CBF over the first six days of life. Furthermore, Cooke et al, using venous occlusion plethysmography in the term human infant, showed quite clearly that CBF was constant between three and 24 hours and that in fact flow was rather higher during the first two hours. ${ }^{4}$

Contrary to the statement of Levene et al, nowhere in our paper have we suggested that the major cerebral arteries perform the main role in regulating blood flow'. Clearly in the normal brain perfusion is closely coupled to metabolic demand in the tissues and important local mechanisms regulating flow must exist. We do contend that the regulation of $\mathrm{CBF}$ is unusual in occurring at more than one arterial level including the major cerebral arteries. The quoted work of Ahmann et al suggests that in the anterior cerebral arteries of only three preterm infants studied the vessels had an immature muscle coat, whereas in eight infants of a wide range of gestations studied by ourselves the muscle wall was well developed. It seems illogical that Levene et al are prepared to accept that the major cerebral arteries of mature animals and humans are vasoactive, but are unwilling to accept the same for neonates. Our technique has been carefully validated in vitro. Appropriate animal models for validation in vivo are not currently available to us and we do not believe that acceptable gold standards for the measurement of CBF in the newborn human exist. We believe that investigators who rely on the use of mean cerebral artery blood velocity as a measure of CBF may be misled.

\section{References}

${ }^{1}$ Rosenberg HS, Klima T, Henderson SR, McNamara DG. Maturation of the aortic isthmus. Cardiovascular Research Center Bulletin 1971;10:47-56.

${ }^{2}$ Pattern BM. Pathology of the heart and blood vessels. Springfield: Charles C Thomas, 1968:80-5.

${ }^{3}$ Rosenberg HS. Coarctation of the aorta: morphology and pathogenetic considerations. In: Rosenberg HS, Bolande RP, eds. Perspectives in pediatric pathology I. Chicago: Year Book Publications, 1973:339-68.

${ }^{4}$ Cooke RWI, Rolfe P, Howat P. Apparent cerebral blood-flow in newborns with respiratory disease. Dev Med Child Neurol 1979;21:154-60.

\section{Interaction between chloramphenicol and acetaminophen}

Sir,

Dr Choonara ${ }^{1}$ raises the possibility that the changes in chloramphenicol pharmacokinetics observed in our study ${ }^{2}$ were unrelated to acetaminophen.

The pharmacokinetics of chloramphenicol could be influenced by many factors including age, underlying 